\title{
The impact of body mass index status on appetite responses and food intake following acute consumption of resistant starch
}

\author{
N.M. Al-Mana and M.D. Robertson \\ Department of Nutritional Sciences, Faculty of Health and Medical Sciences, University of Surrey, Guildford, Surrey, \\ GU2 $7 W G$.
}

Several studies have linked higher intake of dietary fibre (DF) to improved management of body weight ${ }^{(1,2)}$. Appetite studies are frequently conducted only in lean, healthy control subjects and so conclusions derived from normal weight subjects might not be directly transferable to overweight /obese subjects ${ }^{(3)}$. The aim of this investigation was to compare the effect of ingestion of $48 \mathrm{~g}$ of RS on subjective (appetite ratings) and objective (ad libitum energy intake) markers of eating behavior and postprandial changes in plasma glucose, insulin, C-peptide and GLP-1 between lean and overweight /obese healthy males.

Thirty healthy, male subjects participated in this investigation. All subjects were aged between 18-32 y; 20 of normal weight (BMI $20.1-24.7 \mathrm{~kg} / \mathrm{m}^{2}$ ) and 10 overweight/obese (BMI $28-37 \mathrm{~kg} / \mathrm{m}^{2}$ ). In two visits, subjects consumed either the RS supplement or placebo, both of which were incorporated into separate breakfast and lunch meals giving a total of $48 \mathrm{~g}$ DF or $0 \mathrm{~g}$ DF respectively. Subjects recorded their appetite ratings subjectively using visual analogue scales (VAS) every 30 min, while energy intakes were assessed quantitatively from an ad libitum dinner for 7 hours in addition to 24-hour diet diaries. Postprandial blood glucose, insulin, C-peptide and GLP-1 responses were also measured.

We found a significant effect of BMI group on appetite sensation with overweight individuals rating less hunger and prospective food consumption and was almost significant for fullness compared with the lean group $(p=<0.001, p=0.057)$ respectively. However, no significant differences in energy intake at the ad libitum test meal or over a 24 hour period were found. Although glucose and insulin responses were not significantly different after RS or the placebo between both group, obese group had higher insulin concentration and higher C-peptide (time*group, $p<0.001$ ). The $\mathrm{C}$-peptide to insulin ratio also was significantly higher in the obese group compared with the lean group $(p<0.001)$. Our results showed that postprandial plasma GLP-1 concentrations were lower in the obese group $(p=0.009)$.

In conclusion, the observed differences after consumption of RS in the current study may play a role in body weight regulation in groups with varied BMI. Future research is needed to understand the mechanisms for the variability in pre- and post-prandial glycaemic and hormonal responses in individuals with different body mass. Understanding these factors could help in the development of new treatments for obesity.

1. Kendall CW, Esfahani A, Sanders LM et al. (2010) The effect of a pre-load meal containing resistant starch on spontaneous food intake and glucose and insulin responses. $J$ Food Technol 8, 67-73.

2. Higgins JA (2014) Resistant starch and energy balance: impact on weight loss and maintenance. Crit Rev Food Sci Nutr 54, 1158-66.

3. Bodinham CL, Frost GS, Robertson MD (2010) Acute ingestion of resistant starch reduces food intake in healthy adults. Br J Nutr 103, 917-22. 